\title{
Permeability Prediction of Iron Tailings Including Degree of Compaction and Structure
}

\author{
Deqing Gan, Xi Yang $\mathbb{D}$, and Yunpeng Zhang \\ North China University of Science and Technology, Hebei Mining Key Laboratory of Development and Safety Technology, \\ Tangshan, Hebei 063000, China
}

Correspondence should be addressed to Xi Yang; ncst-lzy@ncst.edu.cn

Received 18 June 2019; Accepted 12 August 2019; Published 25 September 2019

Academic Editor: Dimitri Volchenkov

Copyright (C) 2019 Deqing Gan et al. This is an open access article distributed under the Creative Commons Attribution License, which permits unrestricted use, distribution, and reproduction in any medium, provided the original work is properly cited.

\begin{abstract}
The stability of iron tailings dam is affected by the permeability of tailings. Considering the influence of it, it is necessary to analyze the permeability of tailings so as to prevent the recurrence of Brazilian iron tailings dam accidents. Nevertheless, the results of iron tailings permeability from some prediction equations (Terzaghi equation, Hazen equation, and Kozeny equation) cannot be accurate. Iron tailings are various as they can be divided into three categories: (1) silt content is less than 40\%; (2) silt content is more than $40 \%$, while clay content is less than $15 \%$; and (3) clay content is more than $15 \%$ and less than $30 \%$. Correspondingly, three equations are proposed to calculate the disturbed and iron undisturbed tailings permeability for the three types. And more accurate results come from it. The water-flow paths of the iron tailings are blocked after compaction, and the critical pressure of iron tailings blockage is $200 \mathrm{kPa}$. Although the porosity is large, some of the pores are isolated from each other when the pressure is larger than $200 \mathrm{kPa}$. However, porosity becomes too large for permeability calculation after compaction and the calculated permeability gets larger as well (equations (24)-(26)). Correcting the permeability calculation equations is an absolute must. The calculated permeability by the revised equations becomes more accurate (equations (27)-(29)). In fact, the granulometric characteristics necessarily play a vital role in the evolution of the pore interconnections by blocking the water-flow paths and modifying the morphological parameters. More research studies are required to be done in the future.
\end{abstract}

\section{Introduction}

Soil permeability is the ability to allow water to flow under a hydraulic head. It is one of the most significant geotechnical properties of soil and gets involved in the design of retaining structures and earthen dams. In addition, the permeability of tailings has an impact on the stability of tailings dam $[1,2]$. But permeability has not yet been classified as a parameter for design with several constraints related to its measurement $[3,4]$. Many permeability measurements are very tough, time-consuming, and expensive. It is very unfavorable for a wide range of measuring the permeability coefficients. Therefore, many analytical equations have been proposed to predict the permeability of fine-grained soil.

Beven and Germann found that water flowing in soils occurs mainly in macropores. Thus, a capillary model has been proposed to estimate the soil permeability [5]. This model is widely applied for predicting the permeability coefficients. The porous medium consists of straight parallel channels with a cylindrical shape in the model. The permeability coefficient $(K)$ is predicted by the following equation:

$$
K=\frac{p d^{2}}{32}
$$

where $p=$ porosity and $d=$ is the mean diameter of channels.

The approximation of the straight channel is corrected by the curvature $(\tau)$, and the channel is assumed to be oriented in three spatial directions, and the porous medium is considered to be isotropic and homogeneous. The curvature $(\tau)$ makes the prediction of permeability coefficient more accurate. According to Saffman [6], equation (1) becomes 


$$
K=\frac{p d^{2}}{96 \tau^{2}} .
$$

The porous medium consists of tortuous cylindrical channels. The permeability coefficient $(K)$ is expressed as a quadratic function of the characteristic size of the channels. However, for the Carman-Kozeny model, the permeability coefficient $(K)$ is expressed as a function of the specific surface area $\left(A_{\mathrm{s}}\right)$. Both have their own scope of application. The Carman-Kozeny model is as follows [7]:

$$
K=\frac{p^{3}}{k A_{s}^{2} \tau^{2}},
$$

where $k=$ shape factor.

After determining the relevant parameters, the Kozeny equation is as follows [8]:

$$
K=780 \frac{n^{3}}{(1-n)^{2}} d_{\theta}^{2} .
$$

The Terzaghi equation and Hazen equation are also applied for predicting the permeability coefficient. However, the permeability coefficient $(K)$ is expressed as a quadratic function of the particle size in the Hazen equation. In addition, the permeability coefficient $(K)$ is expressed as a quadratic function of the particle size and void ratio in the Terzaghi equation.

The Terzaghi equation is as follows [8]:

$$
K=2 d_{10}^{2} e^{2}
$$

The Hazen equation is as follows [9]:

$$
K=2 d_{10}^{2}
$$

where $K$ is the permeability coefficient of the sample soil at $20^{\circ} \mathrm{C} ; d_{9}$ and $d_{10}$ are, respectively, the sample soil particle diameter $(\mathrm{cm})$ corresponding to the cumulative content of $9 \%$ and $10 \% ; d_{\theta}=d_{20}(\mathrm{~cm}) ; e=$ void ratio; and $n=$ porosity.

As reported by Schwartz et al., the permeability coefficient $(K)$ of a sediment is generally controlled by many factors such as pore dimensions, topology, or connectedness. Thus, the following equation is proposed to predict the permeability coefficient $(K)$ of a sediment [10-15]:

$$
K=\frac{r_{\text {eff }}^{2}}{8 F} \text {. }
$$

The permeability coefficient $(K)$ is expressed as a quadratic function of the effective pore radius $\left(r_{\mathrm{eff}}\right) . r_{\mathrm{eff}}$ cannot be regarded as an actual geometric measure but as a characteristic length scale [16]. By introducing the formation resistivity factor $(F)$ to correct the approximation of channels, equation (7) makes the prediction of permeability coefficient more accurate. The formation resistivity factor $(F)$ combines information about porosity $(\phi)$, connectedness $(\chi)$, and electric tortuosity $(\tau)$ :

$$
F=\phi^{-m}=\tau \phi^{-1}=(\chi \phi)^{-1} \text {. }
$$

As reported by Walker and Glover, the topology of the pore space is described by the packing constant (a) [17]. The sediment permeability coefficient is then estimated with the RGPZ model [15]. The RGPZ model is as follows:

$$
K_{\mathrm{RGPZ}}=\frac{1}{4 a m^{2} F^{2}} d_{\mathrm{eff}}^{2} \text {. }
$$

In order to simplify the calculation process, many existing empirical equations replace these structural variables $(a, m$, and $F)$ with an empirically defined coefficient $[18,19]$. Thus, the RGPZ model can be written as equation (10). It only applies to certain soils:

$$
K_{\mathrm{RGPZ}}=0.00067 d_{\mathrm{eff}}^{2}
$$

where $a=$ sediment packing constant, unitless; $F=$ formation resistivity factor, unitless; $d_{\text {eff }}=$ effective grain diameter, $m$; $r_{\text {eff }}=$ effective pore radius, $m$; and $K=$ permeability, $m^{2}$.

These existed models are mainly based on empirical methods and Darcy's law. Factors considered by these models may not apply to tailings. More factors need to be taken into account for iron tailings. Tailings are different from other soils. It contains a lot of fine particles, such as silt particles and clay particles. The permeability coefficient of tailings varies greatly because of the change in fine particle content. Furthermore, the structure of tailings varies from other soils due to the discharge method of tailings. The bottom tailings are continuously compressed with the increasing height of the tailings dam. Structure and degree of compaction are important factors affecting the permeability of tailings. But these factors have not been considered in the above equations. For avoiding the recurrence of Brazilian tailings dam accidents, it is imperative to analyze the permeability of tailings. In this paper, the permeability properties of iron tailings were analyzed by fine particle content, structure, and degree of compaction. A series of new equations with improved accuracy for calculating the permeability coefficient of iron tailings were proposed, which plays a major role in analyzing the stability of tailings dams.

\section{Materials and Experimental Setup}

2.1. Preparation of Experimental Samples. The iron tailings samples (Figure 1) used in the test are taken from the Chenkeng tailings reservoir (Figure 1) in Fujian Province, China. These samples maintain the original internal structure of the tailings. First, we apply Vaseline to the inner wall of the ring cutter which prevents water from escaping from the wall of the ring cutter. The diameter of the ring cutter is $61.8 \mathrm{~mm}$, and the height is $40 \mathrm{~mm}$. Then, four ring cutters are loaded into a sampler (Figure 1). The samplers are used to take the iron tailings samples at different distances from the tailings dam. The sampling depth of the iron tailings samples is the same. The sampler must be sealed immediately to keep the water from draining after sampling. The dry density of the samples is about $2.10 \mathrm{~g} / \mathrm{cm}^{3}$ [20].

2.2. Experimental Setup. Experiments were conducted by a permeameter that consists of a water outlet, a water inlet, an air outlet, two switches, a bottom cover, a top cover, a pressure cap, and three screws, as shown in Figure 2. 

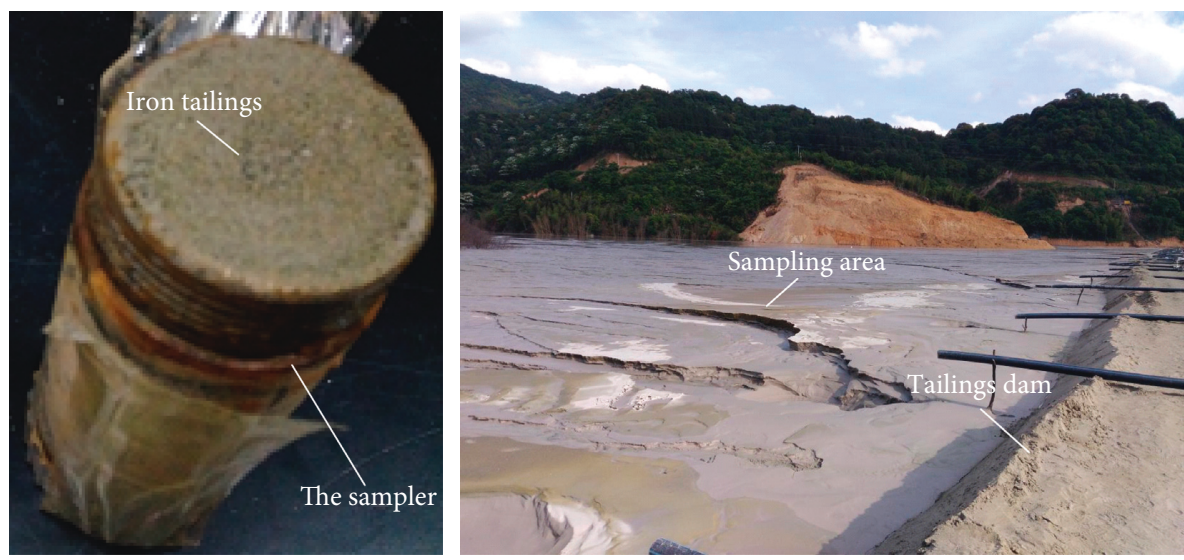

FIgURE 1: The sampler and sampling area.

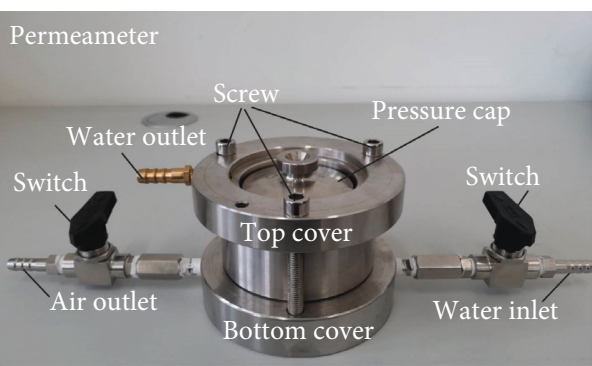

Figure 2: Permeameter.

The schematic of the experimental setup is shown in Figure 3. A steel tape is affixed vertically to a wall for recording the water head height. Then, a glass tube with $10 \mathrm{~mm}$ diameter and $1.5 \mathrm{~m}$ length was vertically affixed to the steel tape for generating water head pressure. A hose is bestowed to connect the lower end of the tube with the permeameter inlet. The height of the hose is the same as the height of the permeameter inlet. Then, fill the tube with water. The height of the water in the tube reaches the initial water head height. The water flows from the upright tube into the permeameter through the inlet, and then, it passes through the experimental samples from the bottom to the top before running out from the outlet. The accuracy of the test will be affected by the bubbles in the permeameter and tube. Thus, they have to be completely removed by injecting tap water and shaking the tube before starting a test.

Based on Darcy's law, the permeability coefficient of the tailings can be calculated using the following equation in the experiment:

$$
K=2.3 \frac{\eta_{T} a L}{\eta_{20} A\left(t_{2}-t_{1}\right)} \log \frac{H_{1}}{H_{2}},
$$

where $L=$ the height of the sample $(\mathrm{cm}) ; a=$ the cross-sectional area of the tube $\left(\mathrm{cm}^{2}\right) ; t_{1}$ and $t_{2}$ are the start and end time which the water inside the tube falls from $H_{1}$ to $H_{2}(\mathrm{~s})$; $H_{1}=$ the initial water head height, $H_{2}=$ the final water head height $(\mathrm{cm}) ; \eta_{20}=$ the dynamic viscosity of water at $20^{\circ} \mathrm{C}$; and $\eta_{T}=$ the dynamic viscosity of water at $T^{\circ} \mathrm{C}(\mathrm{kPa})[20]$.

First, the initial water head height $\left(H_{1}\right)$ and time $\left(t_{1}\right)$ should be recorded. Then, we open the water inlet switch

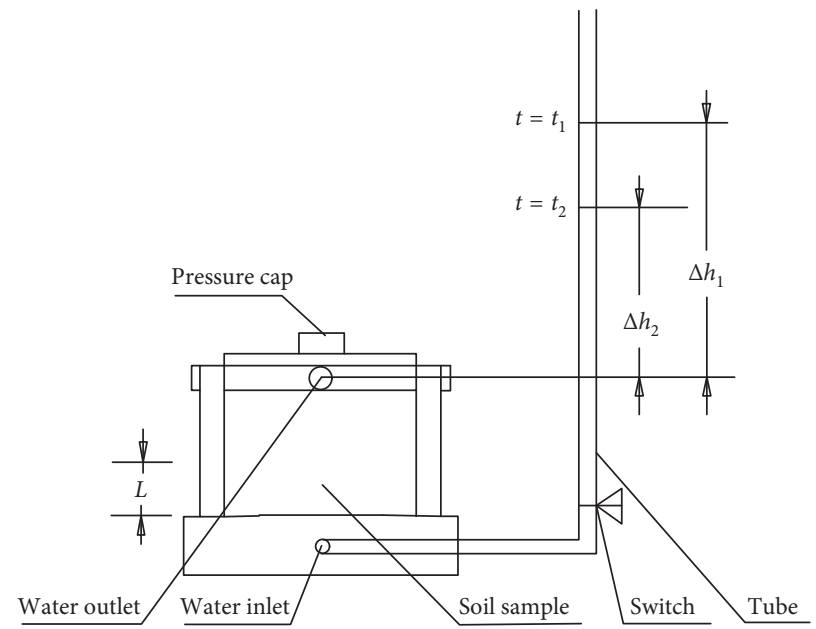

FIGURE 3: Schematic plot of the experimental setup.

(Figure 2) and record the final water head height $\left(\mathrm{H}_{2}\right)$ and corresponding time $\left(t_{2}\right)$. The above process is repeated 4 times. Finally, based on equation (11), the permeability coefficient of the undisturbed iron tailings is calculated. The average value is used as the permeability coefficient of this tailings sample [20].

After a permeability test, a compaction test is performed by compaction device that consists of a displacement monitor, two dowel bars, and some weights as shown in Figure 4 . We can apply different pressures to the tailings sample by adding the weights. After 24 hours, the compaction test is completed. When the displacement and corresponding pressure have been recorded, another permeability test is performed. The effect of compaction on the permeability of the tailings can be figured out by compaction tests.

Since the tests of permeability and compaction of the undisturbed iron tailings have been completed, each undisturbed iron tailings sample was dried and made into a disturbed sample with the same dry density as the undisturbed iron tailings sample. The disturbed tailings are uniform while the undisturbed tailings are layered. The test of the disturbed iron tailings is then performed, which is 


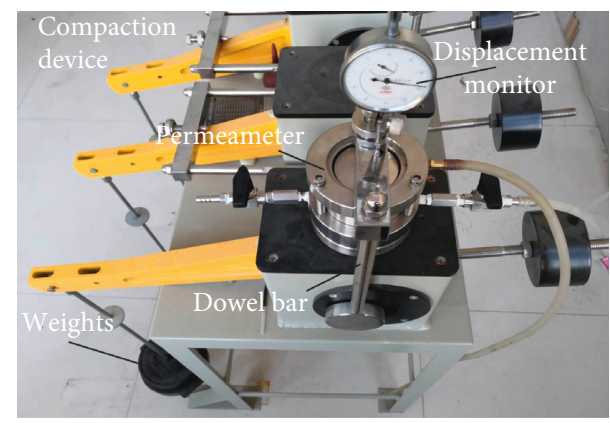

Figure 4: Compaction device.

identical to the undisturbed ones. The disturbed iron tailings have no deposition structure and are uniform. The effect of the structure on the permeability of the tailings can be analyzed by comparing the data of the disturbed tailings with the undisturbed one.

A total of three series of tests were conducted. First, 12 groups (1-12 series) of iron tailings permeability tests were performed to figure out the influence of fine particle content on permeability coefficients. Second, 5 groups (2-5 series) of iron tailings permeability tests were performed to figure out the difference of permeability coefficients between the undisturbed tailings and disturbed tailings. Third, 13 groups (3-13 series) of iron tailings permeability and compaction tests were performed to figure out the permeability coefficients of compressed tailings.

\section{Test Results}

3.1. The Influence of Fine Particle Content on Permeability Coefficients. 12 groups of iron tailings permeability tests were performed. The gradation curves are shown in Figure 5.

The influence of silt content on the permeability of iron tailings has been shown in Figure 6(a). This figure shows that the permeability coefficients are decreasing with the increase in the silt content at first. The reason behind this decreasing trend is that the void ratio decreases as the clay content increases. But the permeability coefficients increase slightly, when the silt content exceeds $40 \%$. The reason behind this increasing trend is that the void ratio increases when the silt content exceeds $40 \%$ [21]. Then, the permeability coefficients continue to decrease because of the increase in clay content.

The influence of clay content on the permeability of iron tailings has been shown in Figure 6(b). This figure shows that the permeability coefficients are increasing with the raise of the clay content at first. The reason behind this increasing trend is that the void ratio increases when the silt content exceeds $40 \%$ or the clay content is less than $15 \%$. Although the void ratio is increased, the effective void ratio is decreased. Therefore, the permeability coefficients decrease when the clay content exceeds $15 \%$.

Tailings contain a wide range of particle sizes, which is different from other soils. Different permeability occurs in different particle size ranges and content. Therefore, it is necessary to classify tailings in order to make a better analysis of their permeability.

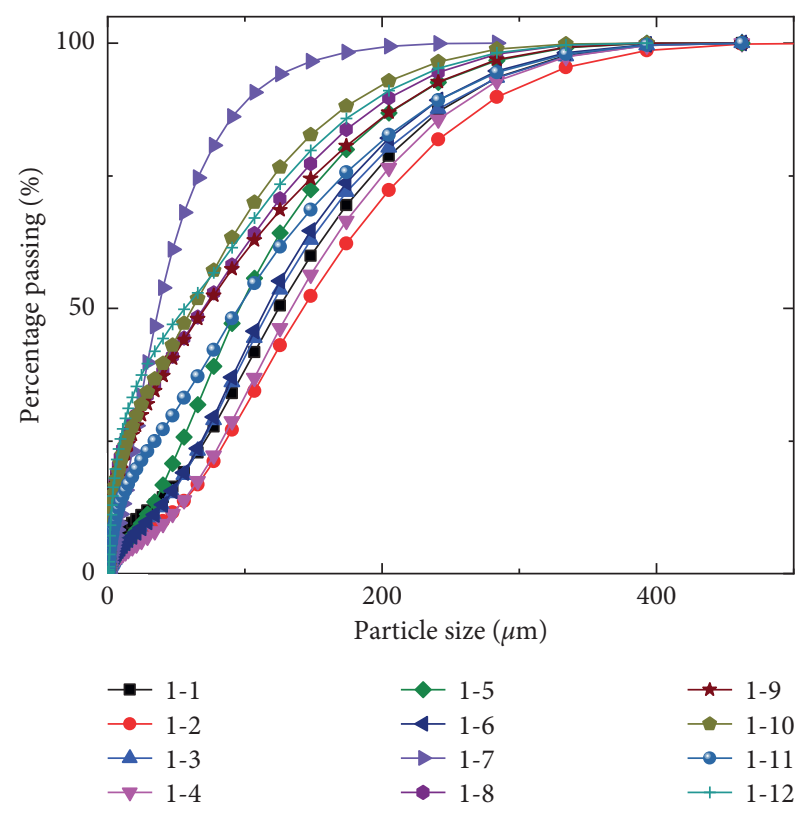

Figure 5: Gradation curves of iron tailings.

3.2. Comparison of Permeability Coefficients between Undisturbed Tailings and Disturbed Tailings. 5 groups of iron tailings permeability tests were performed. The gradation curves are shown in Figure 7.

The structure of tailings is different from other soils because of the discharge method of tailings. The influence of structure on the permeability of iron tailings has been shown in Figure 8. The permeability coefficients of the disturbed tailings are larger than those of the undisturbed ones because of sedimentary structure. The distributed tailings are uniform, and the coarse and fine particles of the undisturbed tailings are distributed in different layers. Therefore, the permeability coefficients of the undisturbed tailings are more affected by fine particles. Its permeability coefficients are smaller.

3.3. The Permeability Coefficients of Compressed Tailings. 13 groups of iron tailings permeability and compaction tests were performed. The gradation curves are shown in Figure 9. The iron tailings are subjected to different pressures at different depths. Therefore, each permeability test contains 8 pressure levels $(0 \mathrm{kPa}, 50 \mathrm{kPa}, 100 \mathrm{kPa}$, $200 \mathrm{kPa}, 400 \mathrm{kPa}, 800 \mathrm{kPa}, 1600 \mathrm{kPa}$, and $3200 \mathrm{kPa}$ ) based on the depth of the iron tailings. In total, 104 permeability tests under different pressure conditions were performed, as shown in Figure 10.

The influence of pressure on the permeability of iron tailings has been shown in Figure 10. This figure shows that the permeability coefficients are decreasing with the increasing pressure. The permeability coefficients begin to slowly decrease when the pressure exceeds $800 \mathrm{kPa}$. The evolution of the permeability is becoming less significant with the low degree of compaction. The permeability channel will be blocked when the degree of compaction intensified [22]. The bottom tailings are continuously 


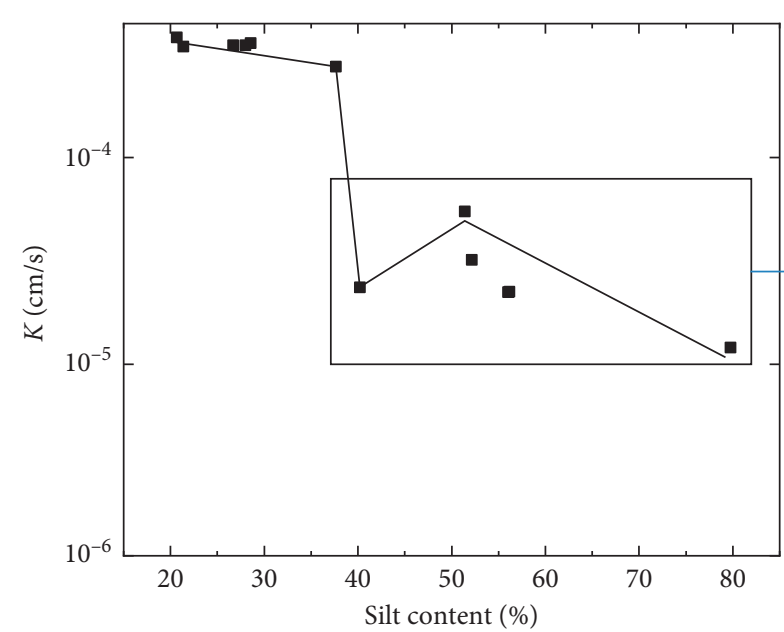

(a)

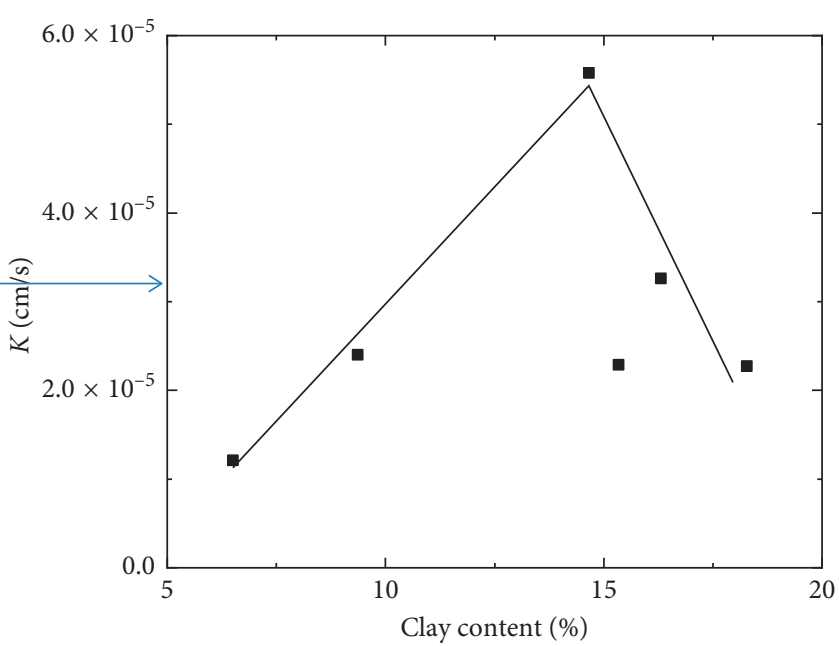

(b)

FIGURE 6: Permeability coefficient curves: variation of permeability coefficients with (a) silt content and (b) clay content.

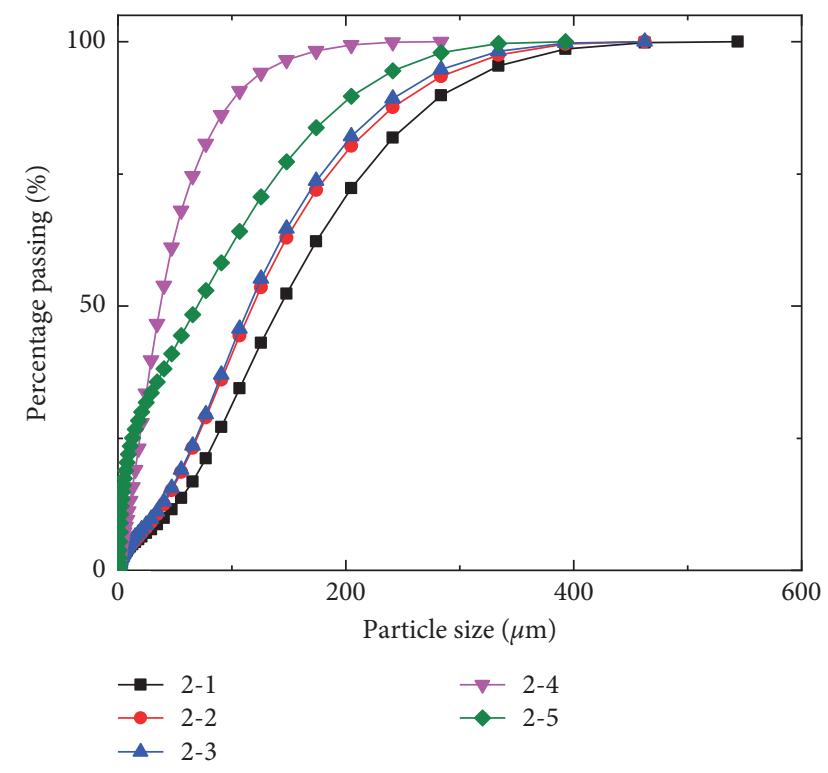

Figure 7: Gradation curves of iron tailings.

compressed when the height of the tailings dam increases. The void ratio cannot be effectively used to calculate the permeability coefficients on condition that the permeability channel blocked. Therefore, it is necessary to take pressure into consideration so as to accurately calculate the permeability coefficients in different degrees of compaction.

\section{Discussion}

4.1. Comparison between Experimental Permeability Coefficients and Those Provided by Permeability Soil Models. Three equations among all approaches discussed in the Introduction section were selected-Terzaghi equation, Hazen equation, and Kozeny equation. The permeability coefficients estimated from the three previously selected models are given in Figures 11-13.

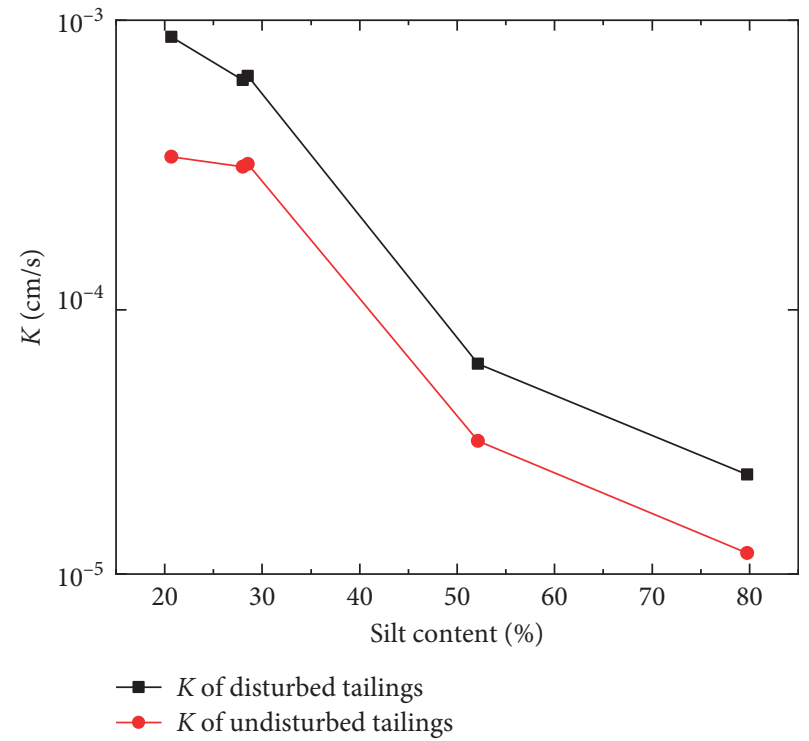

Figure 8: Permeability coefficient of the disturbed and undisturbed tailings.

All the undisturbed tailings samples were calculated by equations (5) and (6) in Figures 11 and 12. All calculated permeability coefficients are less than the measured permeability. Only particle size $\left(d_{10}\right)$ and void ratio have been considered in equations (5) and (6). However, the tailings have a larger particle size range. The particle size and void ratio used to calculate the permeability coefficients of tailings in different particle size ranges should be varying. In addition, the structure and compaction are not considered in equations (5) and (6). Therefore, they failed to correctly predict the permeability of the undisturbed tailings. These models may be essentially meant for sand, for which they provide good estimates [23].

All the undisturbed tailings samples were calculated by equation (4), which is shown in Figure 13. Most calculated permeability is larger than the measured permeability. The high permeability values calculated by the Kozeny approach 


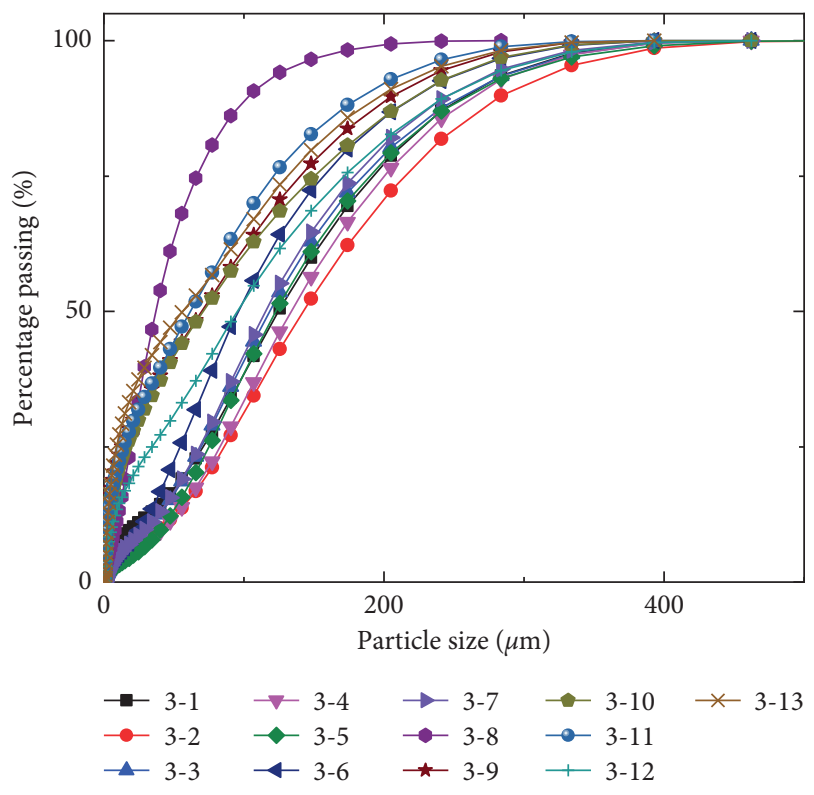

FIgURE 9: Gradation curves of iron tailings.

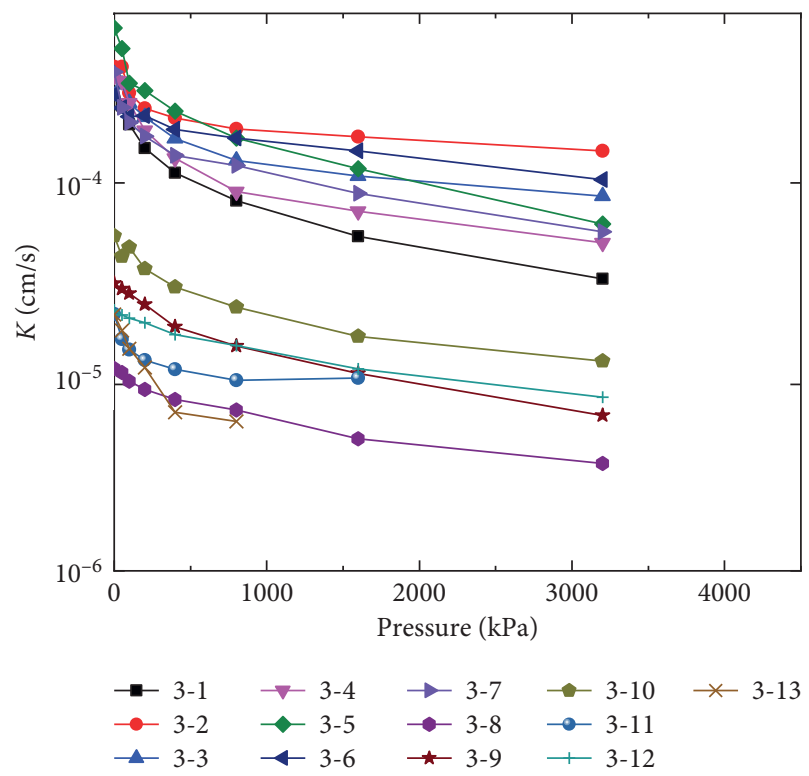

FIgURE 10: Variation of permeability coefficients with pressure.

can be explained by an imprecise estimation of specific surface area, as well as by the possibility that the model is not valid for some types of soil [22]. In addition, the structure and compaction are not considered in equation (4).

4.2. Models for Permeability Prediction of Tailings. Based on Darcy's law, the virtual discharge velocity $(v)$ of the sample becomes

$$
v=K J
$$

The actual discharge velocity $\left(v^{\prime}\right)$ of the sample becomes larger than the virtual discharge velocity $(v)$. The actual discharge velocity $\left(v^{\prime}\right)$ depends on the following expression:

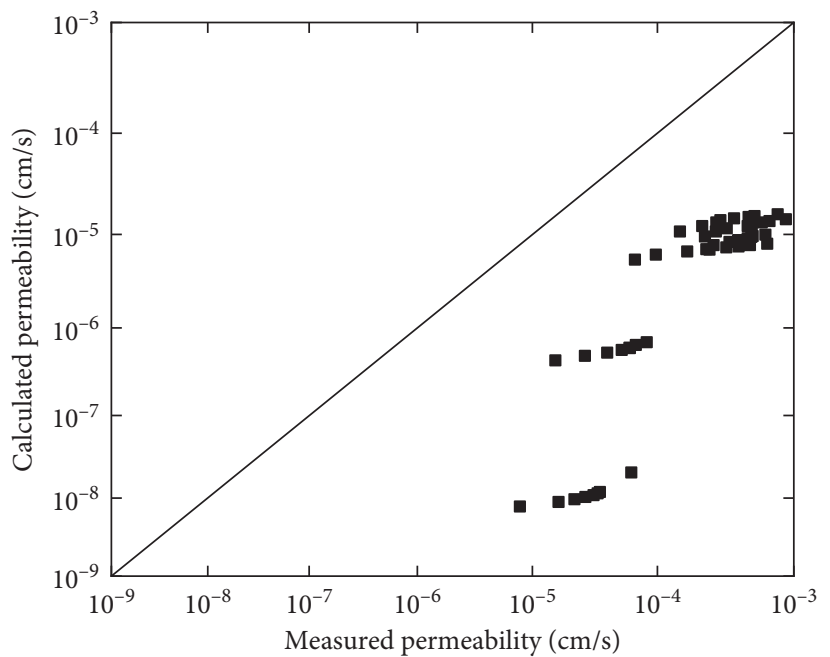

FIGURE 11: Crossplots of the calculated permeability by equation (5) and the measured permeability.

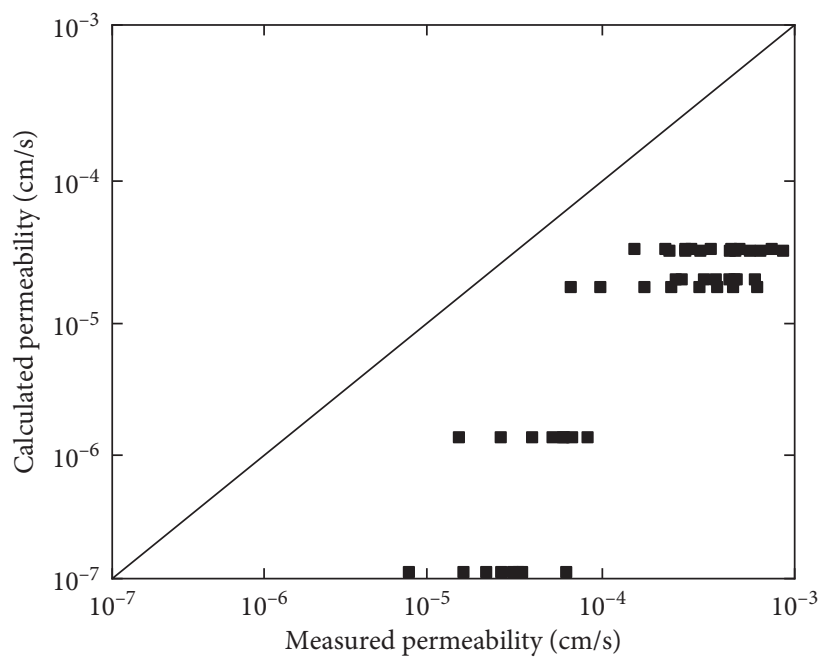

FIGURE 12: Crossplots of the calculated permeability by equation (6) and the measured permeability.

$$
v=n v^{\prime} .
$$

An assemblage of unconnected fluid conduits model the pore system geometry resulting from granular packing of discrete particles [24]. The actual discharge velocity $\left(v^{\prime}\right)$ is given by

$$
v^{\prime}=\frac{g R^{2}}{8 v} J_{\mathrm{h}} .
$$

Thus, the virtual discharge velocity $(v)$ is given by

$$
v=\frac{g R^{2} n}{8 v} J_{\mathrm{h}} .
$$

The radius of conduit $(R)$ can be replaced by average pore diameter $\left(D_{0}\right)$. Then, the virtual discharge velocity $(v)$ is given by 


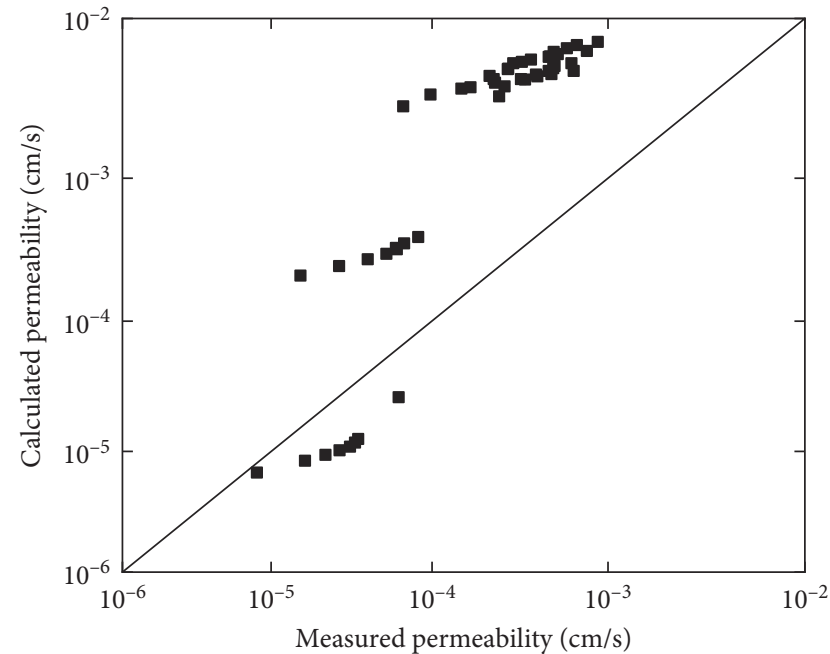

FIGURE 13: Crossplots of the calculated permeability by equation (4) and the measured permeability.

$$
\begin{aligned}
& v=\frac{g\left(D_{0} / 2\right)^{2} n}{8 v} J_{\mathrm{h}}, \\
& v=\frac{g\left(D_{0}\right)^{2} n}{32 v} J_{\mathrm{h}} .
\end{aligned}
$$

The actual hydraulic gradient $\left(J_{\mathrm{h}}\right)$ is determined by the following expression:

$$
J_{\mathrm{h}}=\frac{J}{T}
$$

The correction coefficient $\alpha_{2}$ is given by

$$
\alpha_{2}=\frac{1}{T}
$$

Thus, the virtual discharge velocity $(v)$ is given by

$$
v=\alpha_{2} \frac{g D_{0}^{2} n}{32 v} J .
$$

The average pore diameter $\left(D_{0}\right)$ is the key to calculate the permeability coefficient. Based on the research of Institute of Water Resources and Hydropower Research (China), the average pore diameter $\left(D_{0}\right)$ is given by [25]

$$
D_{0}=0.63 n d_{20} .
$$

Thus, the permeability coefficient $(K)$ is given by

$$
K=234 n^{3} d_{20}^{2}
$$

where $v$ is the virtual discharge velocity; $v^{\prime}$ is the actual discharge velocity; $n$ is the porosity; $K$ is the permeability coefficient; $J_{\mathrm{h}}$ is the actual hydraulic gradient; $J$ is the hydraulic gradient; $R$ is the radius of conduit; $D_{0}$ is the average pore diameter; $v$ is the dynamic viscosity of water, $v=0.013 \mathrm{~cm}^{2} / \mathrm{s}$; $d_{20}$ is the sample soil particle diameter $(\mathrm{cm})$ corresponding to the cumulative content of $20 \% ; \alpha_{2}$ is the correction coefficient, $\alpha_{2}=0.25$; and $g$ is the gravity acceleration.
4.3. Tailings Classification. Tailings contain a wide range of particle sizes. Different permeability occurs in different particle size ranges and content. Therefore, a better analysis of their permeability requires the tailings to be classified. Based on the research by Thevanayagam [26] and Thevanayagam and Martin [27], the contact state of the soil is affected by FC (fine particle content of particle size below $0.075 \mathrm{~mm}$ ). And there is a threshold [28]. The permeability coefficient decreases rapidly when the FC (FC= silt content) exceeds $40 \%$ in Section 3.1. Benson et al. [29] believe that the permeability coefficient fell off rapidly when the fine content exceeds $40 \%$, which is similar to the test results in Section 3.1. The calculation formula for $\mathrm{FC}_{\text {th }}$ (the threshold of FC) used to calculate the $\mathrm{FC}_{\text {th }}$ of iron tailings was proposed by Rahman et al. [28]. The $\mathrm{FC}_{\text {th }}$ of iron tailings is approximately $40 \%$ [21]. Therefore, the iron tailings could be classified into two categories according to the $\mathrm{FC}_{\mathrm{th}}$.

Figure 6(b) shows that the permeability coefficients increase with the raise in the clay content at first and then they decrease when the clay content exceeds $15 \%$. There is a threshold for clay content, too. It has been figured out by Koltermann and Gorelick [30] and is shown in Figure 14. The threshold of clay content is approximately $15 \%$, and it is similar to the test results in Figure 6(b). The silt content is constant in Figure 14, but the clay content and silt content of iron tailings are increasing together because of the discharge method. The permeability coefficients increase with the increasing clay content when the silt content exceeds $40 \%$ or the clay content is less than $15 \%$. The permeability coefficients decrease when the clay content exceeds $15 \%$ because the effective void ratio is reduced.

Iron tailings can be divided into three categories: (1) silt content is less than $40 \%$; (2) silt content is larger than $40 \%$ and clay content is less than $15 \%$; and (3) clay content is $15 \%-30 \%$. Tailings will become clay tailings when the clay content is larger than $30 \%$. Tailings rarely contain more than $30 \%$ of clay particles. Therefore, the research has been not conducted in this paper, and the classifications of clay tailings are in need of further study.

\subsection{Permeability Coefficient Calculation of the Disturbed} Tailings Samples. The permeability of different types of iron tailings should be calculated by multiple methods. 2-1, 2-2, and 2-3 belong to the first type of iron tailings. Their permeability could be calculated by equation (21). The results are shown in Table 1, which becomes more accurate.

The permeability of iron tailings varies when the silt content is larger than $40 \%$ and the clay content is less than $15 \%$. Therefore, $n$ should give place to $n_{\text {silt }} \cdot d_{10}$ is used to calculate the average pore diameter of silt [21]. The permeability of the second iron tailings (2-4) could be calculated by equation (22), and more accurate results were obtained and are shown in Table 1:

$$
K=234 n_{\text {silt }}^{3} d_{20}^{2}
$$

where $n_{\text {silt }}$ is the porosity of iron tailings silt particles and $e_{\text {silt }}$ is the silt particle void ratio [28, 30, 31].

The permeability of iron tailings changes when the clay content is larger than $15 \%$. Therefore, $n$ should be 


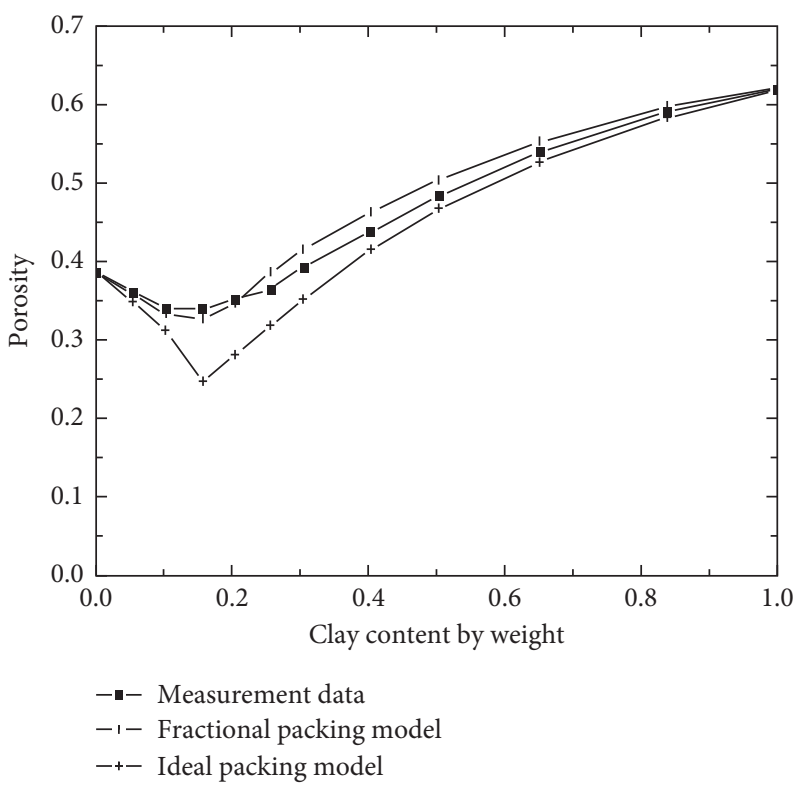

FIGURE 14: Variation of clay content with porosity.
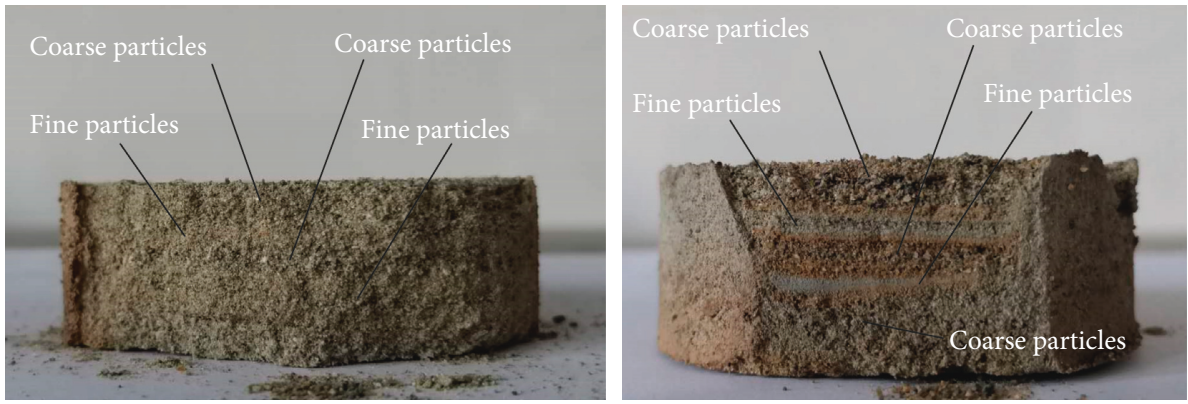

FIGURE 15: The undisturbed iron tailings samples.

substituted by $n_{\text {clay }}$. The permeability of the third iron tailings (2-5) could be calculated by equation (23). The results are more accurate and shown in Table 1 :

$$
K=234 n_{\text {clay }}^{3} d_{20}^{2},
$$

where $n_{\text {clay }}$ is the porosity of iron tailings clay particles, $e_{\text {clay }}$ is the clay particle void ratio, and CC is the clay content of iron tailings.

\subsection{Permeability Coefficient Calculation of the Undisturbed} Tailings Samples. The structure of tailings is different from other soils because of the discharge and deposition method. Iron tailings contain coarse and fine layers (Figure 15). The permeability coefficient of the undisturbed tailings samples is more susceptible to fine particles than that of the disturbed tailings samples. Therefore, the permeability coefficients of the undisturbed tailings are less than those of the disturbed tailings, which resulted from a change in the local porosity of the tailings. By calculation, it was found out that the permeability coefficient of the first type of undisturbed iron tailings was mainly affected by $n /$ $n_{\text {silt }}$. This can be calculated by equation (24). In addition, the permeability coefficients of the second and the third type of undisturbed iron tailings are mainly affected by $n_{\text {silt }} / n_{\text {clay. }}$. They can be calculated by equations (25) and (26).

$1-1,1-2,1-3,1-4$, and 1-6 belong to the first type of iron tailings whose permeability can be calculated by equation (24). The results are shown in Table 2:

$$
K=\frac{n}{n_{\text {silt }}} 234 n^{3} d_{20}^{2} .
$$

$1-5,1-7$, and 1-11 belong to the second type of iron tailings whose permeability can be calculated by equation (25). The results are shown in Table 2:

$$
K=\frac{n_{\text {silt }}}{n_{\text {clay }}} 234 n_{\text {silt }}^{3} d_{10}^{2} .
$$

$1-8,1-9,1-10$, and 1-12 belong to the third type of iron tailings whose permeability can be calculated by equation (26). The results are shown in Table 2: 
TABLE 1: The measured permeability and calculated permeability of the disturbed tailings.

\begin{tabular}{lccccccc}
\hline Number & $n$ & $n_{\text {silt }}$ & $n_{\text {clay }}$ & $d_{20}(\mu \mathrm{m})$ & Measured permeability $(\mathrm{cm} / \mathrm{s})$ & Calculated permeability $(\mathrm{cm} / \mathrm{s})$ & Ratio \\
\hline $2-1$ & 0.3955 & - & - & 74.17 & $8.80 \times 10^{-4}$ & $7.96 \times 10^{-4}$ \\
$2-2$ & 0.4076 & - & - & 59.73 & $6.33 \times 10^{-4}$ & $5.65 \times 10^{-4}$ \\
$2-3$ & 0.3980 & - & - & 59.73 & $6.52 \times 10^{-4}$ & $5.26 \times 10^{-4}$ \\
$2-4$ & 0.4146 & 0.4703 & - & 15.66 & $2.43 \times 10^{-5}$ & $1.69 \times 10^{-5}$ \\
$2-5$ & 0.2990 & - & 0.7234 & 7.91 & $6.33 \times 10^{-5}$ & 0.81 \\
\hline
\end{tabular}

Ratio $=$ calculated permeability $\div$ measured permeability.

TABLE 2: The measured permeability and calculated permeability of undisturbed tailings.

\begin{tabular}{lcccccc}
\hline Number & $n$ & $n_{\text {silt }}$ & $n_{\text {clay }}$ & $d_{20}(\mu \mathrm{m})$ & Measured permeability $(\mathrm{cm} / \mathrm{s})$ & Calculated permeability $(\mathrm{cm} / \mathrm{s})$ \\
\hline $1-1$ & 0.3641 & 0.6820 & - & 58.73 & $3.21 \times 10^{-4}$ & $2.08 \times 10^{-4}$ \\
$1-2$ & 0.3955 & 0.7598 & - & 74.17 & $3.47 \times 10^{-4}$ & $4.14 \times 10^{-4}$ \\
$1-3$ & 0.4076 & 0.7107 & - & 59.73 & $3.21 \times 10^{-4}$ & $3.24 \times 10^{-4}$ \\
$1-4$ & 0.4056 & 0.7614 & - & 72.17 & $3.17 \times 10^{-4}$ & $4.33 \times 10^{-4}$ \\
$1-5$ & 0.4051 & 0.6438 & 0.9569 & 47.36 & $2.58 \times 10^{-4}$ & $2.88 \times 10^{-4}$ \\
$1-6$ & 0.3980 & 0.6984 & - & 59.73 & $3.28 \times 10^{-4}$ & $3.00 \times 10^{-4}$ \\
$1-7$ & 0.4146 & 0.4703 & 0.9158 & 15.66 & $1.21 \times 10^{-5}$ & $8.66 \times 10^{-6}$ \\
$1-8$ & 0.2990 & 0.4499 & 0.7234 & 7.91 & $3.26 \times 10^{-5}$ & $3.45 \times 10^{-5}$ \\
$1-9$ & 0.3237 & 0.4822 & 0.7656 & 10.15 & $5.58 \times 10^{-5}$ & 0.92 \\
$1-10$ & 0.3606 & 0.5010 & 0.7862 & 9.2 & $2.29 \times 10^{-5}$ & 0.71 \\
$1-11$ & 0.3914 & 0.6153 & 0.8728 & 22.9 & $2.40 \times 10^{-5}$ & 1.06 \\
$1-12$ & 0.3566 & 0.4972 & 0.7520 & 5.71 & $2.27 \times 10^{-5}$ & 1.22 \\
\hline
\end{tabular}

Ratio $=$ calculated permeability $\div$ measured permeability.

$$
K=\frac{n_{\text {silt }}}{n_{\text {clay }}} 234 n_{\text {clay }}^{3} d_{20}^{2} .
$$

Based on the permeability equations of disturbed iron tailings, the permeability equations of undisturbed iron tailings are corrected. The results are more accurate, but the theoretical basis needs further verification.

4.6. Consideration of Compaction Characteristics in Prediction of Permeability of Undisturbed Tailings Samples. The ratio of the first iron tailings is approximately 1 when the pressure is less than $200 \mathrm{kPa}$. It will increase when the pressure is larger than $200 \mathrm{kPa}$ (Figure 16), which indicates that the calculated permeability is too large. As the pressure increases, the porosity decreases. In addition, the blockage also occurs when the pressure is larger than $200 \mathrm{kPa}$. The greater the pressure is, the more frequently the blockage occurs [22]. $P$ is pressure $(\mathrm{kPa})$.

The ratio and $\lg P$ are fitted when the pressure is larger than $200 \mathrm{kPa}$. The results are shown in Figure 17. The relationship between ratio change caused by clogging and $\lg P$ is linear. Based on this, equation (24) can be corrected to equation (27). The crossplots of the calculated permeability using equation (27) and the measured permeability are shown in Figure 18. It is more accurate than other equations (Terzaghi equation, Hazen equation, and Kozeny equation):

$$
K=\frac{\left(n / n_{\text {silt }}\right) 234 n^{3} d_{20}^{2}}{1.6923 \lg P-2.5995}
$$

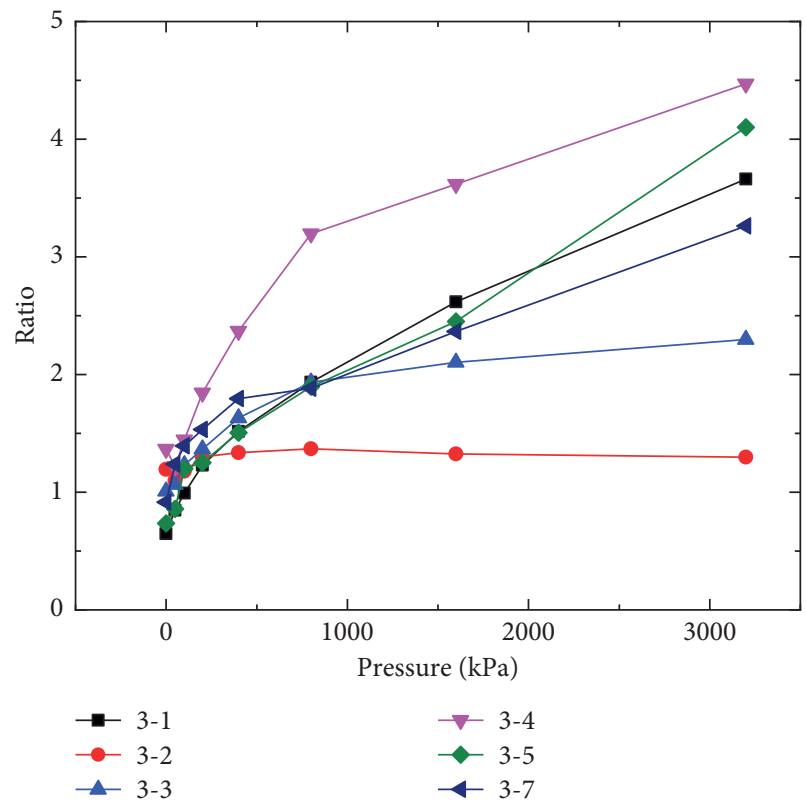

Figure 16: Variation of pressure with ratio (ratio $=$ calculated permeability by equation $(24) \div$ measured permeability).

The ratio of the second iron tailings does not change much when the pressure is less than $200 \mathrm{kPa}$ and it will increase when the pressure is larger than $200 \mathrm{kPa}$ (Figure 19), which means that the calculated permeability is too large. As the pressure increases, the porosity decreases. In addition, the blockage also occurs when the pressure is larger 


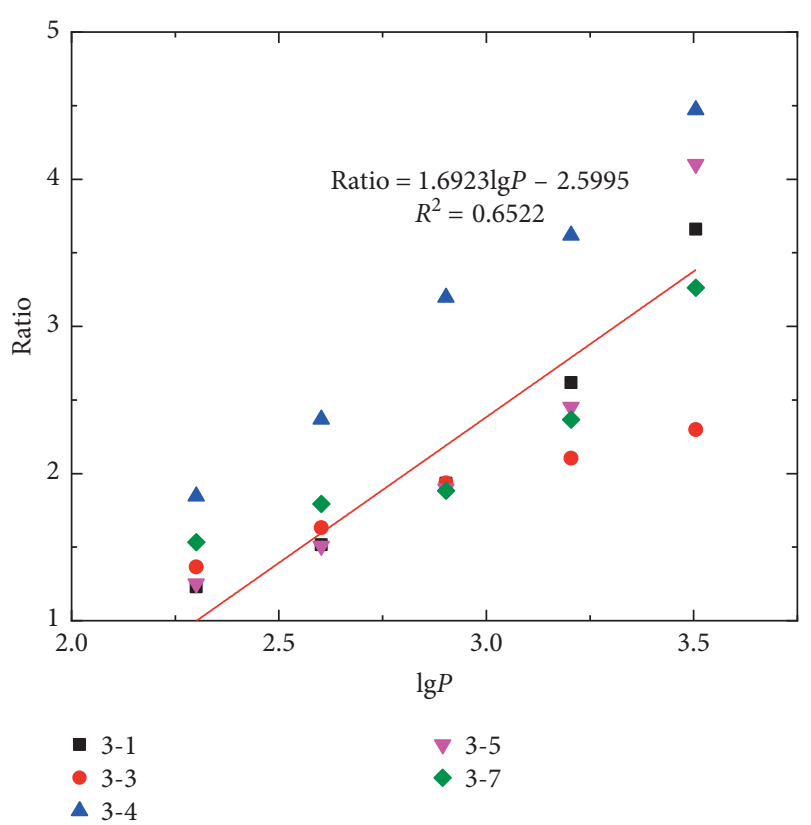

FIGURE 17: Variation of $\lg P$ with ratio (ratio= calculated permeability by equation $(24) \div$ measured permeability).

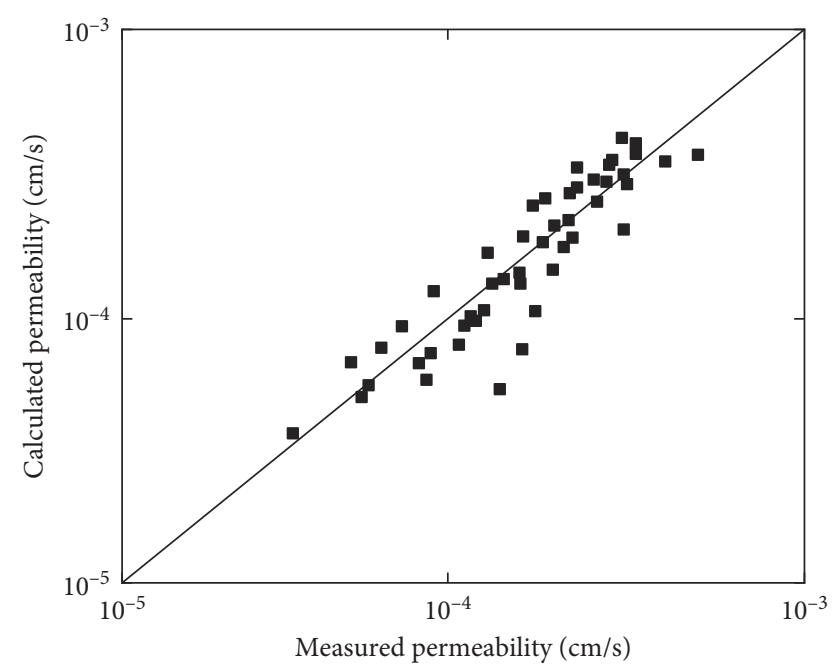

FIGURE 18: Crossplots of the calculated permeability by equation (27) and the measured permeability.

than $200 \mathrm{kPa}$. The greater the pressure is, the more frequently the blockage occurs $[22,32-34] . P$ is pressure $(\mathrm{kPa})$.

The ratio and $\lg P$ are fitted when the pressure is larger than $200 \mathrm{kPa}$. The results are shown in Figure 20. The relationship between ratio change caused by clogging and $\lg P$ is linear. Based on this, equation (25) can be corrected to equation (28). The crossplots of the calculated permeability using equation (28) and the measured permeability are shown in Figure 21. It is more accurate than other equations (Terzaghi equation, Hazen equation, and Kozeny equation):

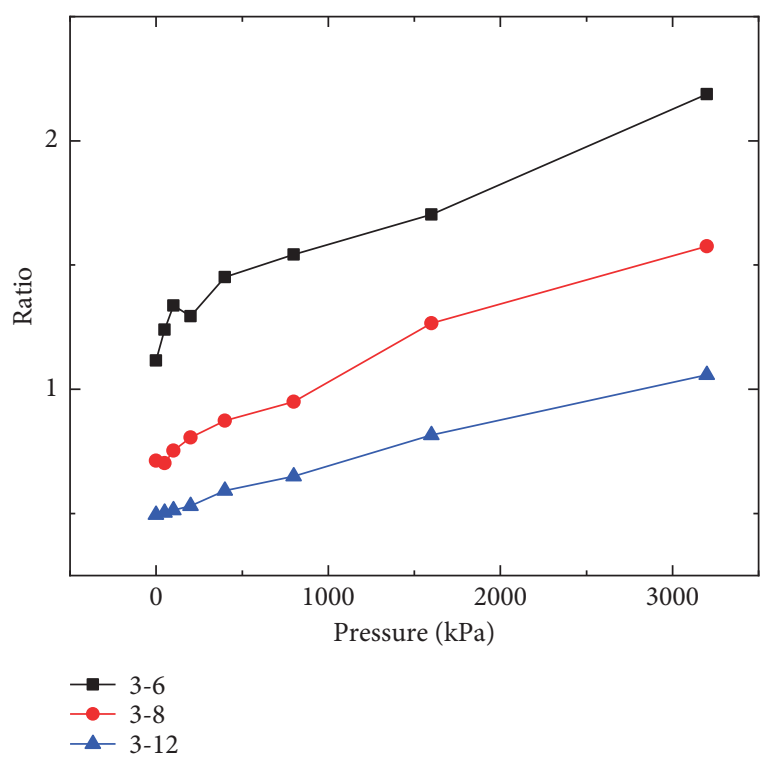

FIgURE 19: Variation of pressure with ratio (ratio $=$ calculated permeability by equation $(25) \div$ measured permeability).

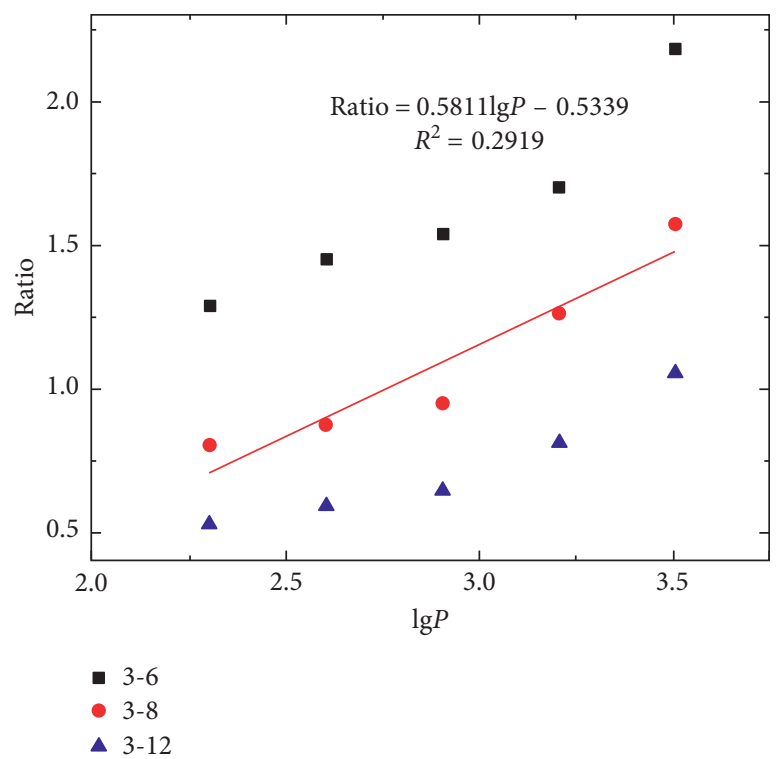

FIgURe 20: Variation of $\lg P$ with ratio (ratio = calculated permeability by equation $(25) \div$ measured permeability).

$$
K=\frac{\left(n_{\text {silt }} / n_{\text {clay }}\right) 234 n_{\text {silt }}^{3} d_{10}^{2}}{0.5881 \lg P-0.5393} .
$$

The ratio of the third iron tailings is approximately 1 when the pressure is less than $200 \mathrm{kPa}$. It will increase when the pressure is larger than $200 \mathrm{kPa}$ (Figure 22), which means that the calculated permeability is too large. When the pressure increases, the porosity decreases. In addition, the blockage also occurs when the pressure is larger than $200 \mathrm{kPa}$. The greater the pressure is, the more frequently the blockage occurs $[4,22,35-37] . P$ is pressure $(\mathrm{kPa})$. 


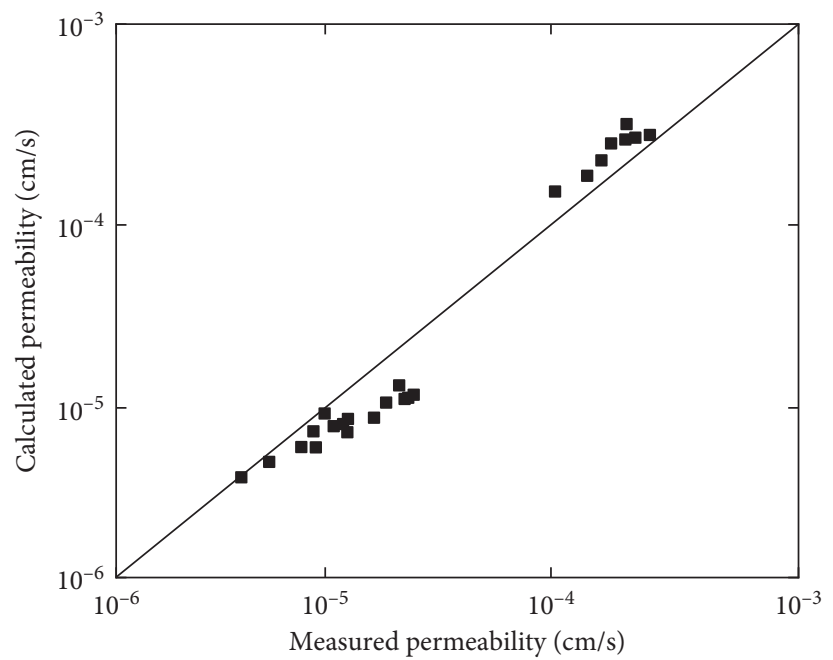

FIGURE 21: Crossplots of the calculated permeability by equation (28) and the measured permeability.

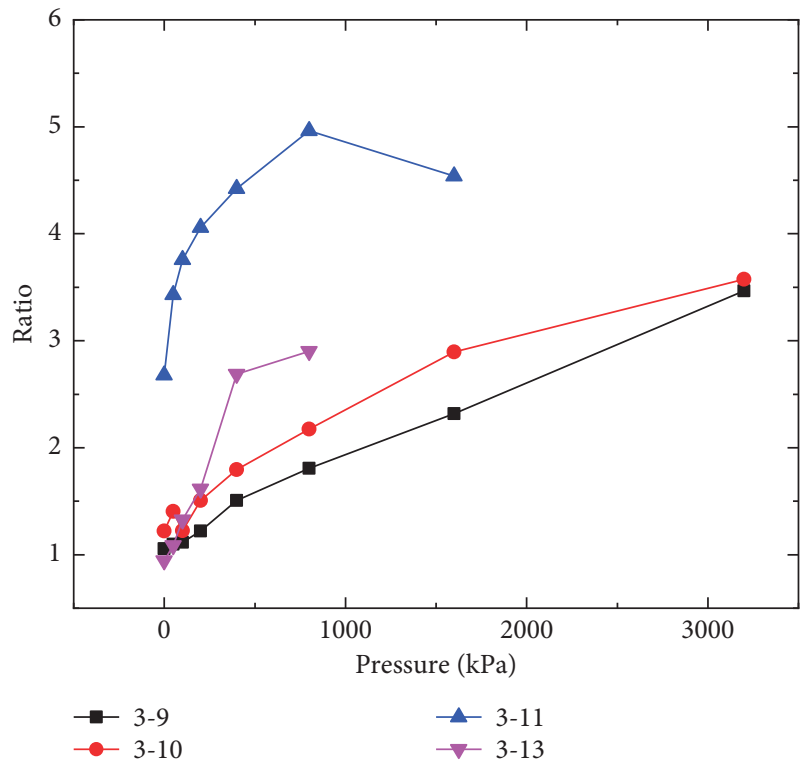

FIGURE 22: Variation of pressure with ratio (ratio= calculated permeability by equation $(26) \div$ measured permeability).

The ratio and $\lg P$ are fitted when the pressure is larger than $200 \mathrm{kPa}$. The results are shown in Figure 23. The relationship between ratio change caused by clogging and $\lg P$ is linear. Based on this, equation (26) can be corrected to equation (29). The crossplots of the calculated permeability using equation (29) and the measured permeability are shown in Figure 24. It is more accurate than other equations (Terzaghi equation, Hazen equation, and Kozeny equation):

$$
K=\frac{\left(n_{\text {silt }} / n_{\text {clay }}\right) 234 n_{\text {clay }}^{3} d_{20}^{2}}{1.5038 \lg P-1.449} .
$$

The water-flow paths are blocked (Figure 25) after compaction. The critical pressure of iron tailings blockage is

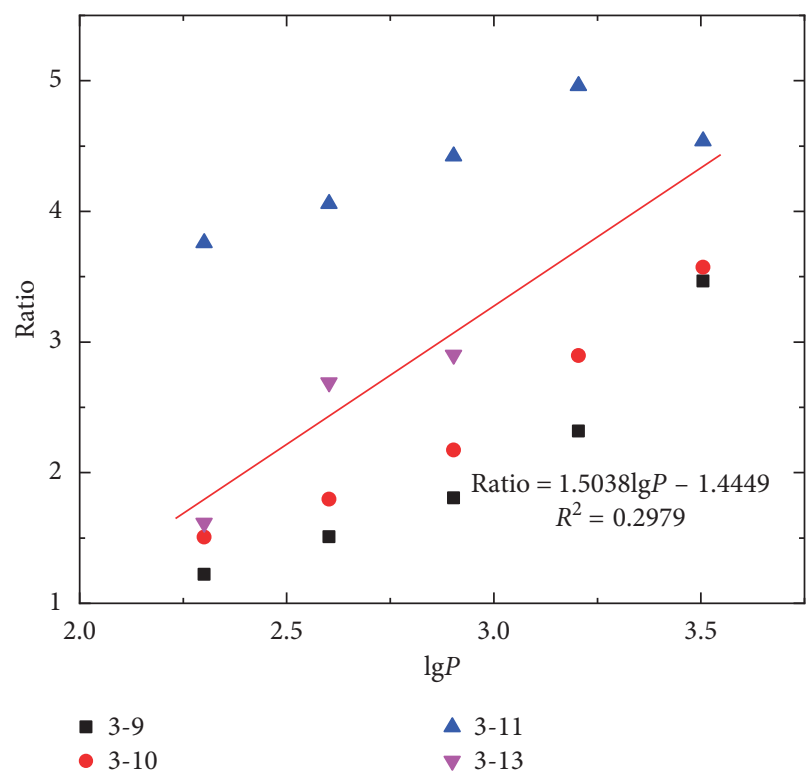

FIGURE 23: Variation of $\lg P$ with ratio (ratio $=$ calculated permeability by equation $(26) \div$ measured permeability).

$200 \mathrm{kPa}$. Although the porosity is large, some of the pores are isolated from each other when the pressure is larger than $200 \mathrm{kPa}$. Porosity is too large for permeability calculation. Therefore, the calculated permeability by porosity is too large (equations (24)-(26)). It is necessary to rectify the permeability calculation equations, and the calculated permeability drawing from the revised equations becomes more accurate (equations (27)-(29)). In fact, the granulometric characteristics necessarily play a vital role in the evolution of the pore interconnections by blocking the water-flow paths and by modifying the morphological parameters $[7,22,38,39]$. More factors about compression tailings need to be considered. Simultaneously, a more accurate model needs to be built to improve $R^{2}$ in Figures 17, 20, and 23. This requires further research in the future. 


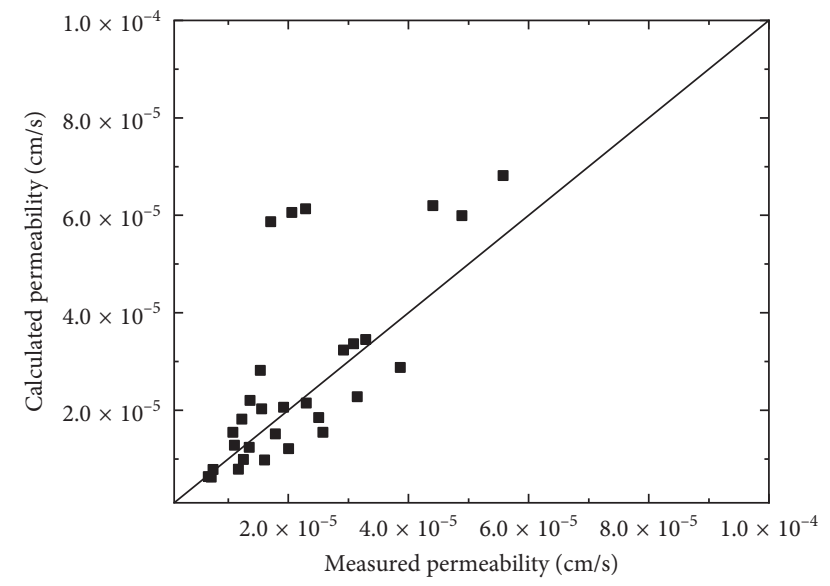

FIGURE 24: Crossplots of the calculated permeability by equation (29) and the measured permeability.

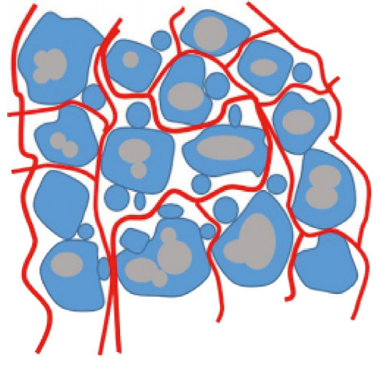

Before compaction

Soil grains

Textural porosity

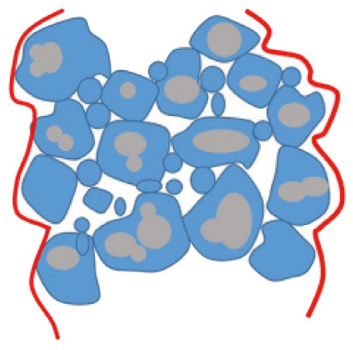

After compaction

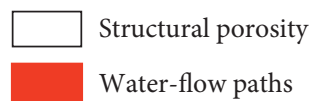

FIgURe 25: Evolution of water-flow paths with compaction.

\section{Conclusion}

The stability of iron tailings dam is affected by the permeability of iron tailings that varies from other soils. Accurate calculations of the iron tailings permeability cannot be obtained by the prediction equations (Terzaghi equation, Hazen equation, and Kozeny equation):

(1) Tailings at different locations on the tailings dam contain diversified particle sizes because of tailings discharge. The classification of iron tailings is desired to accurately calculate the permeability. Then, the iron tailings falls into three categories: (1) silt content is less than $40 \%$; (2) silt content is larger than $40 \%$ and clay content is less than $15 \%$; and (3) clay content is $15 \%-30 \%$. Iron tailings will become clay tailings when the clay content is larger than $30 \%$, which rarely happens. Therefore, the research has been not conducted in this paper and the classification of clay tailings requires further research in the future.

(2) Three equations have been proposed to calculate the disturbed iron tailings permeability, and the permeability is accurate. The discharge and deposition method lead to the difference of structure of iron tailings from other soils. Iron tailings contain coarse and fine layers (Figure 15). Therefore, the permeability coefficients of the disturbed tailings are larger than those of the undisturbed tailings. Besides, the permeability coefficient of the first type of undisturbed iron tailings is mainly affected by $n / n_{\text {silt }}$, while the second and the third type of it are mainly affected by $n_{\text {silt }} / n_{\text {clay }}$. Three equations have been proposed to calculate the three types of undisturbed iron tailings permeability, and the permeability is accurate.

(3) The water-flow paths get blocked (Figure 25) after compaction. The critical pressure of iron tailings blockage is $200 \mathrm{kPa}$. Although the porosity is large, some of the pores are isolated from each other when the pressure becomes larger than $200 \mathrm{kPa}$. Thus, the conclusion can be drawn that the porosity is more than appropriate for the permeability calculation and the calculated permeability is too large (equations (24)(26)). It is of importance to correct the permeability calculation equations, and the permeability by the revised equations is getting more accurate (equations (27)-(29)). In fact, the granulometric characteristics necessarily play an essential role in the evolution of the pore interconnections by blocking the water-flow paths and modifying the morphological parameters. This requires further research in the future.

\section{Data Availability}

The data used to support the findings of this study are included within the article.

\section{Conflicts of Interest}

The authors declare no conflicts of interest.

\section{Acknowledgments}

This research was mainly supported by the National Natural Science Foundation of China (51774137) and National Key Technologies Research \& Development Program (2017YFC0804609).

\section{References}

[1] C. Qi, A. Fourie, Q. Chen, and Q. Zhang, "A strength prediction model using artificial intelligence for recycling waste tailings as cemented paste backfill," Journal of Cleaner Production, vol. 183, pp. 566-578, 2018.

[2] W. Sun, H. Wang, and K. Hou, "Control of waste rock-tailings paste backfill for active mining subsidence areas," Journal of Cleaner Production, vol. 171, pp. 567-579, 2018.

[3] C. D. Shackelford, C. H. Benson, T. Katsumi, T. B. Edil, and L. Lin, "Evaluating the hydraulic conductivity of GCLs permeated with non-standard liquids," Geotextiles and Geomembranes, vol. 18, no. 2-4, pp. 133-161, 2000.

[4] A. A. Aldeef and M. T. Rayhani, "Hydraulic performance of compacted clay liners (CCLs) under combined temperature and leachate exposures," Waste Management, vol. 34, no. 12, pp. 2548-2560, 2014. 
[5] K. Beven and P. Germann, "Macropores and water flow in soils," Water Resources Research, vol. 18, no. 5, pp. 1311-1325, 1982.

[6] P. G. Saffman, "A theory of dispersion in a porous medium," Journal of Fluid Mechanics, vol. 6, no. 3, pp. 321-349, 1959.

[7] R. P. Chapuis and M. Aubertin, "On the use of the KozenyCarman equation to predict the hydraulic conductivity of soils," Canadian Geotechnical Journal, vol. 40, no. 3, pp. 616-628, 2003.

[8] K. Terzaghi and R. B. Park, Soil Mechanics in Engineering Practice, Water Resources and Electric Power Press, Beijing, China, 1960.

[9] A. Hazen, "Discussion of dams on sand foundation by A.C. Koenig," Transactions American Society of Civil Engineers, vol. 73, pp. 199-203, 1911.

[10] K. M. James, Geotechnical Analysis Principle of Geotechnical Engineering, Nanjing Institute of Technology Press, Nanjing, China, 1998.

[11] L. M. Schwartz, P. N. Sen, and D. L. Johnson, "Influence of rough surfaces on electrolytic conduction in porous media," Physical Review B, vol. 40, no. 4, pp. 2450-2458, 1989.

[12] M. Avellaneda and S. Torquato, "Rigorous link between fluid permeability, electrical conductivity, and relaxation times for transport in porous media," Physics of Fluids A: Fluid Dynamics, vol. 3, no. 11, pp. 2529-2540, 1991.

[13] S. Kostek, L. M. Schwartz, and D. L. Johnson, "Fluid permeability in porous media: comparison of electrical estimates with hydrodynamical calculations," Physical Review B, vol. 45, no. 1, pp. 186-195, 1992.

[14] Y. Bernabé and A. Revil, "Pore-scale heterogeneity, energy dissipation and the transport properties of rocks," Geophysical Research Letters, vol. 22, no. 12, pp. 1529-1532, 1995.

[15] P. W. Glover, I. I. Zadjali, and K. A. Frew, "Permeability prediction from MICP and NMR data using an electrokinetic approach," Geophysics, vol. 71, no. 4, pp. F49-F60, 2006.

[16] P. W. Glover and E. Walker, "Grain-size to effective pore-size transformation derived from electrokinetic theory," Geophysics, vol. 74, no. 1, pp. E17-E29, 2009.

[17] E. Walker and P. W. J. Glover, "Permeability models of porous media: characteristic length scales, scaling constants and timedependent electrokinetic coupling," Geophysics, vol. 75, no. 6, pp. E235-E246, 2010.

[18] W. C. Krumbein and G. D. Monk, "Permeability as a function of the size parameters of sedimentary particles," Transactions of the American Institute of Mining and Metallurgical Engineers, vol. 1492, pp. 153-163, 1943.

[19] P. W. Glover, "What is the cementation exponent? A new interpretation," The Leading Edge, vol. 28, no. 1, pp. 82-85, 2009.

[20] M. Zhang, X. Zhu, G. Yu et al., "Permeability of muddy clay and settlement simulation," Ocean Engineering, vol. 104, pp. 521-529, 2015.

[21] D. Gan, X. Yang, and Y. Zhang, "Experimental analysis on permeability characteristics of iron tailings," Mathematical Problems in Engineering, vol. 2019, Article ID 6539846, 11 pages, 2019.

[22] H. Ranaivomanana, A. Razakamanantsoa, and O. Amiri, "Permeability prediction of soils including degree of compaction and microstructure," International Journal of Geomechanics, vol. 17, no. 4, pp. 1-11, 2017.

[23] A. Neumann, J. Möbius, H. C. Hass, W. Puls, and J. Friedrich, "Empirical model to estimate permeability of surface sediments in the German Bight (North Sea)," Journal of Sea Research, vol. 127, pp. 36-45, 2017.
[24] G. Kovacs, "Analytical model for particle migration within base soil-filter system," Journal of Geotechnical and Geoenvironmental Engineering, vol. 123, pp. 100-109, 1981.

[25] Institute of Water Resources and Hydropower Research (China), The 8th Episode of the Scientific Research Papers of the Institute of Water Resources and Hydropower Research, Water Conservancy Publishing House, Beijing, China, 1982.

[26] S. Thevanayagam, "Effect of fines and confining stress on undrained shear strength of silty sands," Journal of Geotechnical and Geoenvironmental Engineering, vol. 124, no. 6, pp. 479-491, 1998.

[27] S. Thevanayagam and G. R. Martin, "Liquefaction in silty soils-screening and remediation issues," Soil Dynamics and Earthquake Engineering, vol. 22, no. 9-12, pp. 1035-1042, 2002.

[28] M. M. Rahman, S. R. Lo, and C. T. Gnanendran, "On equivalent granular void ratio and steady state behaviour of loose sand with fines," Canadian Geotechnical Journal, vol. 45, no. 10, pp. 1439-1456, 2008.

[29] C. H. Benson, H. Zhai, and X. Wang, "Estimating hydraulic conductivity of compacted clay liners," Journal of Geotechnical Engineering, vol. 120, no. 2, pp. 366-387, 1994.

[30] C. E. Koltermann and S. M. Gorelick, "Fractional packing model for hydraulic conductivity derived from sediment mixtures," Water Resources Research, vol. 31, no. 12, pp. 3283-3297, 1995.

[31] H. Lu, C. Qi, Q. Chen, D. Gan, Z. Xue, and Y. Hu, "A new procedure for recycling waste tailings as cemented paste backfill to underground stopes and open pits," Journal of Cleaner Production, vol. 188, pp. 601-612, 2018.

[32] P. J. Kamann, R. W. Ritzi, D. F. Dominic, and C. M. Conrad, "Porosity and permeability in sediment mixtures," Ground Water, vol. 45, no. 4, pp. 429-438, 2007.

[33] J. Han and K. Wang, "Influence of bleeding on properties and microstructure of fresh and hydrated Portland cement paste," Construction and Building Materials, vol. 115, pp. 240-246, 2016.

[34] N. Tregger, A. Gregori, L. Ferrara, and S. Shah, "Correlating dynamic segregation of self-consolidating concrete to the slump-flow test," Construction and Building Materials, vol. 28, no. 1, pp. 499-505, 2012.

[35] S. J. Blott and K. Pye, "Particle size distribution analysis of sand-sized particles by laser diffraction: an experimental investigation of instrument sensitivity and the effects of particle shape," Sedimentology, vol. 53, no. 3, pp. 671-685, 2006.

[36] A. Ahangar-Asr, A. Faramarzi, N. Mottaghifard, and A. A. Javadi, "Modeling of permeability and compaction characteristics of soils using evolutionary polynomial regression," Computers \& Geosciences, vol. 37, no. 11, pp. 1860-1869, 2011.

[37] R. P. Chapuis, "Predicting the saturated hydraulic conductivity of sand and gravel using effective diameter and void ratio," Canadian Geotechnical Journal, vol. 41, no. 5, pp. 787-795, 2004.

[38] J. Alam, M. Muzzammil, H. P. Singh, and P. Gupta, "Permeability of stratified soils for flow normal to bedding plane," Aquatic Procedia, vol. 4, pp. 660-667, 2015.

[39] L. David Suits, T. C. Sheahan, A. Sridharan, and K. Prakash, "Permeability of two-layer soils," Geotechnical Testing Journal, vol. 25, no. 4, pp. 447-448, 2002. 


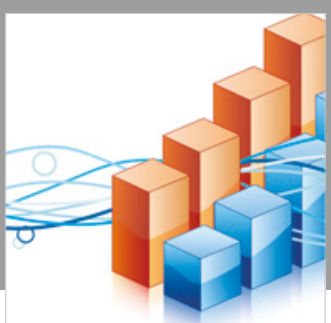

Advances in

Operations Research

\section{-n-m}
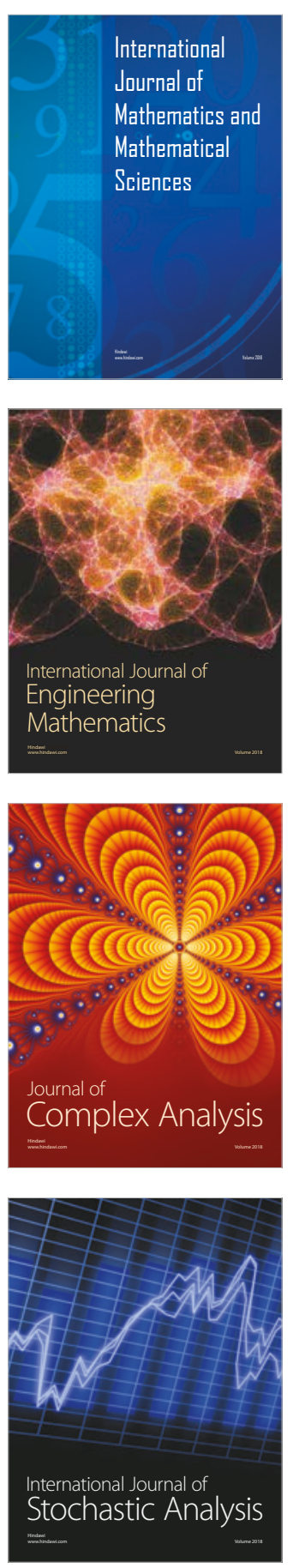
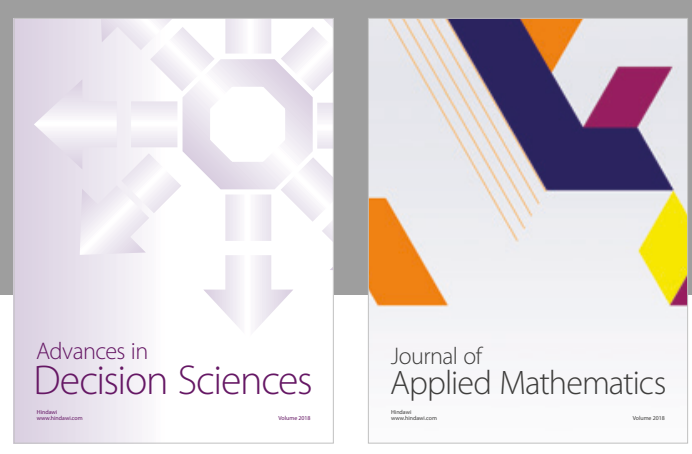

Journal of

Applied Mathematics
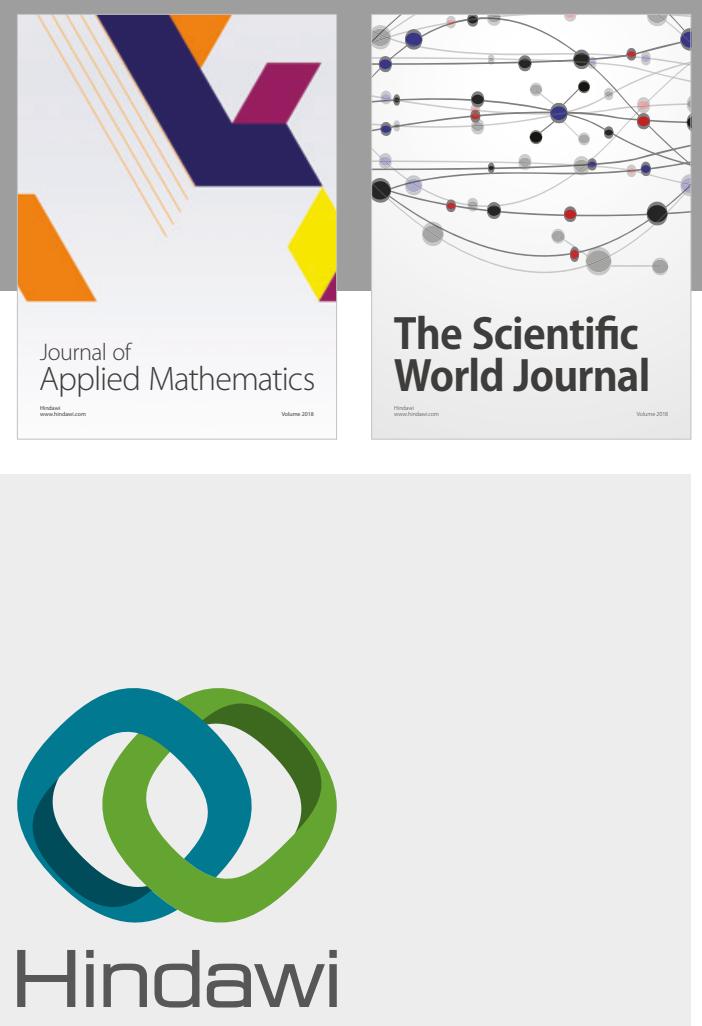

Submit your manuscripts at

www.hindawi.com

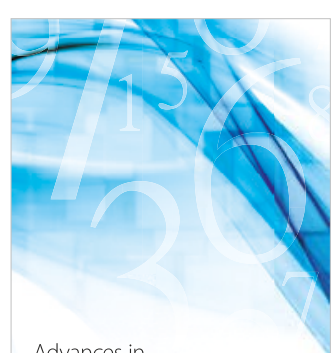

Advances in
Numerical Analysis
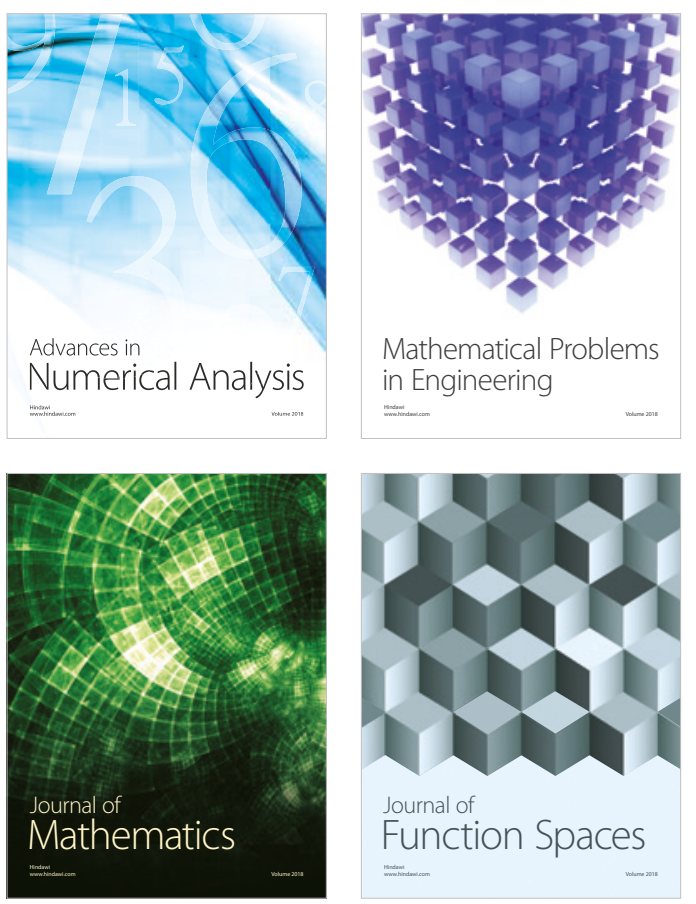

Mathematical Problems in Engineering

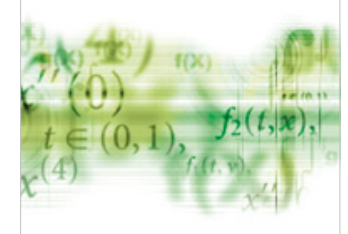

International Journal of

Differential Equations

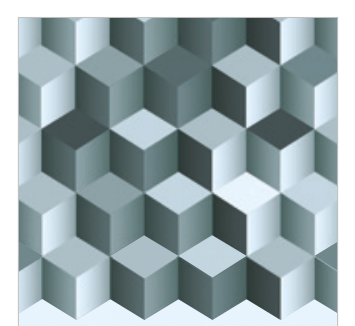

Journal of

Function Spaces
The Scientific

World Journal

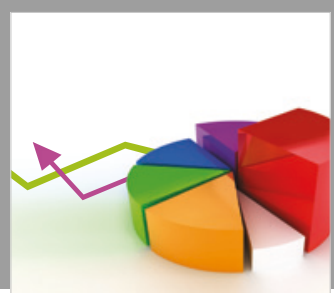

Journal of

Probability and Statistics
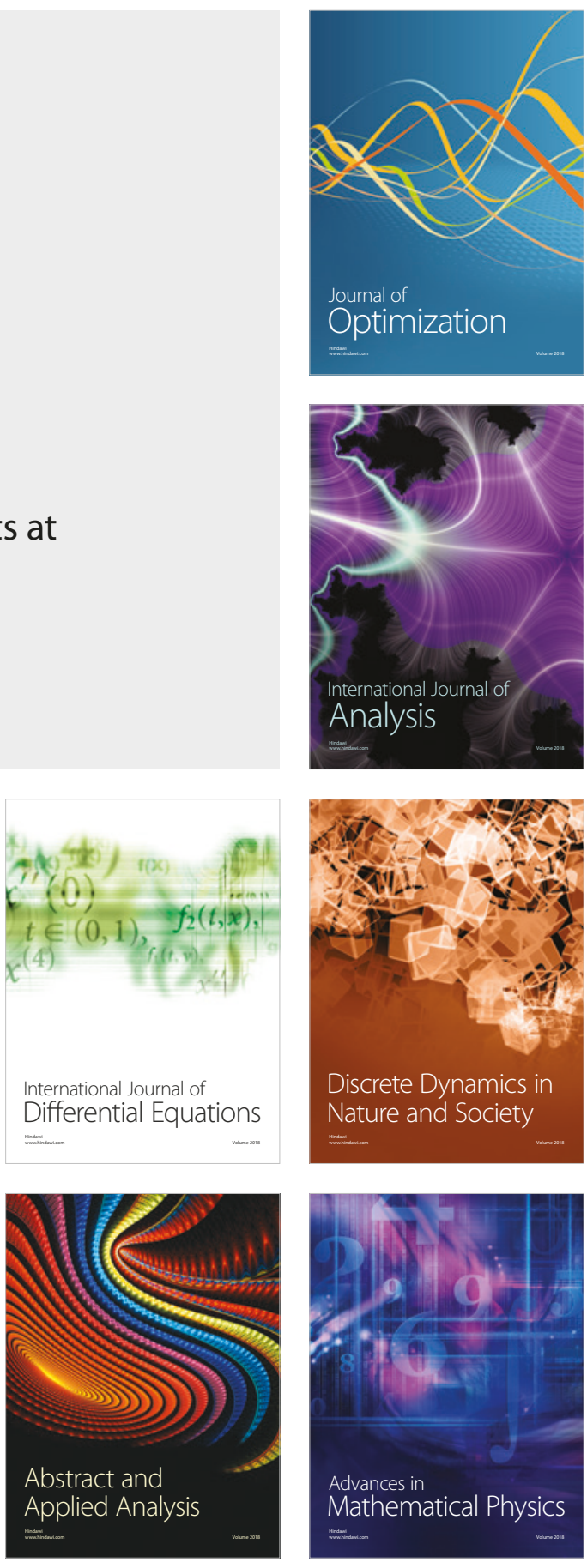